\title{
Biokaasun raaka-aineen korjuukustannus HVP-lohkoilta
}

\author{
Timo Lötjönen ${ }^{1)}$ ja Oiva Niemeläinen ${ }^{2)}$ \\ ${ }^{1)}$ MTT Kasvintuotannon tutkimus, Tutkimusasemantie 15, 92400 Ruukki, timo.lotjonen(at)mtt.fi \\ ${ }^{2)}$ MTT Kasvintuotannon tutkimus, MTT Planta, 31600 Jokioinen, oiva.niemelainen(at)mtt.fi
}

\section{TIIVISTELMÄ}

Suomessa on tällä hetkellä lähes 200000 ha peltoa, jonka sato voitaisiin korjata biokaasun raakaaineeksi. Valtaosa alasta lasketaan kategoriaan "Hoidettu viljelemätön pelto” (HVP). Yleensä HVPlohkot kasvavat monivuotisia nurmikasveja, jotka soveltuisivat hyvin biokaasutukseen. Osa HVPlohkoista on niin pieniä, hankalan muotoisia tai kaukana, ettei niiden sadon hyödyntäminen ole kannattavaa. Mutta joukossa on myös hyviä lohkoja, joista korjuu onnistuu urakointiluokan kalustolla. Tässä tutkimuksessa laskettiin kustannuksia erilaisille biokaasunurmen korjuu- ja varastointiketjuille. Tuloksia voidaan hyvin soveltaa myös säilörehun korjuuseen.

Korjuu- ja varastointiketjuista kaksi perustui ajosilppuriin ja kolme paalaukseen: 1) Ajosilppuri ja varastointi laakasiiloissa, 2) Ajosilppuri ja varastointi muovituubissa, 3) Kanttipaalaus ja käärintä tuubikäärimellä, 4) Pyöröpaalaus ja yksittäiskäärintä combi-koneella ja 5) Pyöröpaalaus ja käärintä tuubikäärimellä.

Korjuu- ja varastointiketjut sisältävät niittomurskauksen, karhotuksen, korjuun, kuljetuksen biokaasulaitokselle (keskimäärin 6 km) ja varastoinnin tarvikkeineen. Paalausketjuihin (3-5) sisältyy myös paalien murskaus syötettäessä biokaasulaitosta. Hankkeessa tehtyjen kasvustomääritysten perusteella HVP-lohkojen korjattavan sadon oletettiin olevan 4 ton ka/ha korjuuta ja vuotta kohden. Tosin sadon määrän vaihtelu oli tutkituilla HVP-lohkoilla hyvin suurta, 1 - 10 ton ka/ha.

Perusskenaariossa korjuu- ja varastointikustannukset asettuivat välille 62 - 68 eur/ton ka, ketjun 3 ollessa edullisin ja ketjujen 1 ja 4 ollessa kalleimpia. Kokonaiskustannusten erot olivat yllättävän pieniä. Pyöröpaalauksessa on iso muovikustannus, kun taas tarkkuussilppuriketjuissa pääoma- ja työvoimakulut ovat suuria. Yksittäin käärittyjä pyöröpaaleja ei voi pitää kovin ekologisena vaihtoehtona, koska muovijätettä tulee paljon. Tarkkuussilppuriketjuissa kuljetuksen kustannus oli noin kolme kertaa suurempi kuin paalausketjuissa.

Käytännössä varsinkin tarkkuussilppuriurakoitsijat korjaavat selvästi tässä oletettuja (400 ha/v) suurempia pinta-aloja. Biokaasunurmen ottaminen mukaan korjuuohjelmaan antaa tähän mahdollisuuden, koska sen korjuu voidaan ajoittaa säilörehun korjuukauden ulkopuolelle. Laskelman mukaan, kun korjuuala kaksinkertaistui 800 ha:iin vuodessa, tarkkuussilppuriketjun kustannukset laskivat noin 56 euroon/ton ka. Hehtaarisadon lisääntyminen 4:stä 7 tonniin ka/ha alensi kustannusta $4-6$ eur/ton ka. Sadon korjaaminen kahdessa erässä yhden korjuukerran sijasta puolestaan kasvatti korjuukustannusta 5 - 8 eur/ton ka.

Koko biokaasulaitoksen taloutta koskevan alustavan laskelman mukaan HVP-nurmella tai säilörehulla toimivan biokaasulaitoksen saaminen kannattavaksi näyttää haasteelliselta, mutta ei aivan mahdottomalta. Laitoksen on oltava iso (luokkaa $500 \mathrm{~kW}_{\mathrm{el}}$ ), lämpö on saatava myytyä täysimääräisesti, heinälle ei voida maksaa kantohintaa sekä korjuu- ja varastointikustannukset on saatava 55 eur/ton ka tuntumaan.

Avainsanat: bioenergia, biokaasu, säilöntä, kesanto, korjuu, varastointi 


\section{Johdanto}

Suomessa on tällä hetkellä lähes 200000 ha peltoa, jonka sato voitaisiin korjata biokaasun raakaaineeksi. Valtaosa alasta lasketaan kategoriaan "Hoidettu viljelemätön pelto” (HVP). Yleensä HVPlohkot kasvavat monivuotisia nurmikasveja, jotka soveltuisivat hyvin biokaasutukseen. Osa HVPlohkoista on niin pieniä, hankalan muotoisia tai kaukana maatilan talouskeskuksesta, ettei niiden sadon hyödyntäminen ole kannattavaa. Mutta joukossa on myös hyviä lohkoja, joista korjuu onnistuu urakointiluokan kalustolla (Niemeläinen ym. 2012). Tässä tutkimuksessa laskettiin kustannuksia erilaisille biokaasunurmen korjuu- ja varastointiketjuille, tavoitteena löytää edullisimmat ketjut. Toisena tavoitteena oli selvittää, auttaisiko merkittävä korjuualan lisääntyminen alentamaan korjuun- ja varastoinnin kustannuksia. Tuloksia voidaan hyvin soveltaa myös säilörehun korjuun kustannusten arviointiin. Lisäksi haluttiin ottaa kantaa siihen, olisiko HVP-nurmea raaka-aineena käyttävä biokaasulaitos millä edellytyksillä kannattava.

\section{Aineisto ja menetelmät}

Työpajatyöskentelyn pohjalta määritettiin järkevimmät biomassan korjuuketjut, jotka soveltuisivat laajamittaiseen, urakointiin perustuvaan nurmen korjuuseen. Tarkastelun kohteiksi otettiin seuraavat ketjut:

1) Ajosilppuri+laakasiilot

2) Ajosilppuri+tuubipakkaus

3) Kanttipaalain+tuubikäärintä

4) Pyöröpaalain (kombi)

5) Pyöröpaalain+tuubikäärintä

Näille laskettiin korjuun ja varastoinnin kustannukset TTS-Kone-ohjelmaa ja taulukkolaskimeen kehitettyä mallia käyttäen. Perusmalleissa pyöröpaalaukseen perustuvilla ketjuilla koneiden käyttömääräksi oletettiin 200 ha/v sekä kanttipaalaukseen ja ajosilppuriin perustuvissa ketjuissa 400 ha/v. Ajosilppuriketjua tarkasteltiin myös 800 ha/v käyttömäärällä. Mallit laadittiin siten, että biomassa varastoidaan kaikissa ketjuissa biokaasulaitoksen pihaan ja laitoksen syötteeksi saadaan paalausketjuissakin biokaasureaktoriin sopivaa silppua, ts. paalausketjut sisältävät paalien silppuamisen. Myös varastosta otto kuului kustannuslaskelmaan. Keskimääräiseksi kuljetusetäisyydeksi on peruslaskelmassa oletettu $6 \mathrm{~km}$. Tuloksia verrattiin urakoitsijoilta kerättyihin toteutuneisiin hintatietoihin (TTS:n urakoitsijahintakysely, Palva 2013) niiltä osin, kun tietoja oli saatavissa.

Projektissa tehtyjen kasvustomääritysten perusteella HVP-lohkojen korjattavan sadon oletettiin olevan 4 ton ka/ha korjuuta ja vuotta kohden (Niemeläinen ym. 2012). Tosin sadon määrän vaihtelu oli tutkituilla HVP-lohkoilla hyvin suurta, 1 - 10 ton ka/ha.

Biokaasulaitoksen kannattavuutta tarkasteltiin Ederin (2012) ja Taavitsaisen (2011) arvojen pohjalta. Taavitsaisen (2011) mukaan sähköteholtaan luokkaa $100 \mathrm{~kW}$ ja sitä pienemmät biokaasulaitokset eivät ole tällä hetkellä kovin kannattavia suurten investointikustannusten takia. Ederin (2012) mukaan peltobiomassoja käyttävän biokaasulaitoksen yksikkökustannukset alenevat selvästi noin 500 kW:n sähkötehoon asti, siitä ylöspäin kustannusten alentuminen on maltillista. Tästä syystä päädyttiin tarkastelemaan laitosta, jonka sähköteho on 500 kW ja lämpöteho 1000 kW.

\section{Tulokset ja tulosten tarkastelu}

Korjuu- ja varastointimallin perustilanteen mukaan (käyttömäärät 200 - 400 ha/v) ketjujen kustannukset asettuivat välille 62 - 68 eur/ton ka, ketjun 3 ollessa edullisin ja ketjujen 1 ja 4 ollessa kalleimpia. Kokonaiskustannusten erot olivat yllättävän pieniä.

Käytännössä varsinkin tarkkuussilppuriurakoitsijat korjaavat selvästi edellä käytettyjä suurempia pinta-aloja. Kun tarkkuussilppuriketjun korjuuala kasvatettiin 800 ha vuodessa, edullisinta oli ajosilppurin tekemän irtosilpun pakkaaminen halkaisijaltaan 2,4 m:n tuubiin (54 e/ ton ka) ja kalleinta säilöntä yksittäin käärittyihin pyöröpaaleihin (68 e/ ton ka) (kuva1). Ajosilppurin ja laakasiilojen yhdistelmää pidetään yleisesti edullisena korjuutapana suurten rehumäärien ollessa kyseessä. Säilöntä- 
muovikustannus onkin menetelmässä hyvin alhainen, mutta kustannuksia tulee siilojen hankintahinnasta ja irtosilppukuormien keveydestä verrattuna paalaukseen perustuviin ketjuihin. Menetelmien välisten erojen pienuus on sikäli hyvä asia, että tilanteen mukaan voidaan valita mikä tahansa kuvan 1 mukainen korjuumenetelmä, eivätkä kustannukset kuitenkaan kasva radikaalisti.

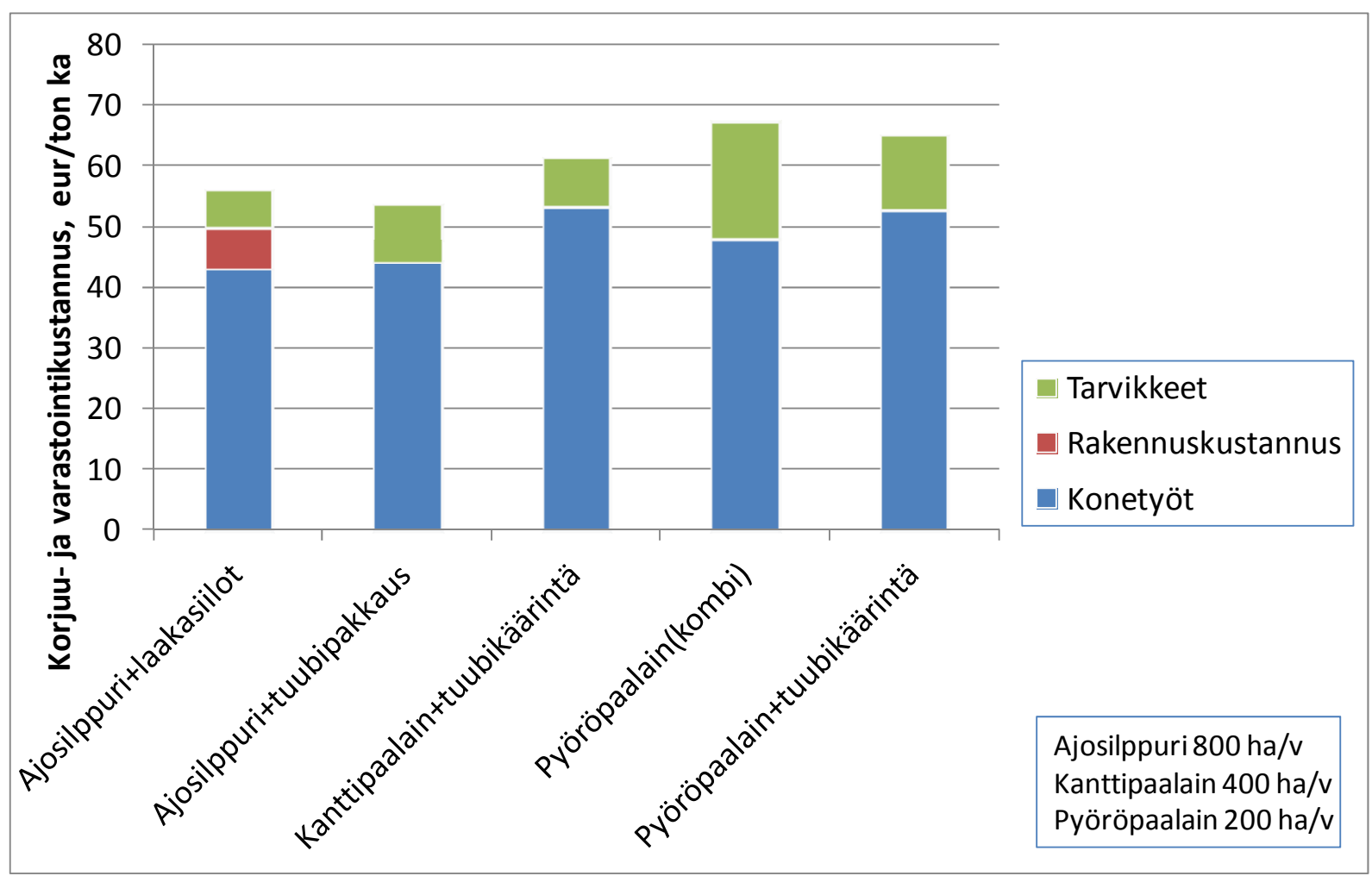

Kuva 1. Biomassan korjuun ja varastoinnin kustannukset urakointitason menetelmillä. Kuljetusetäisyydeksi on oletettu 6 km ja paalaukseen perustuvat menetelmät sisältävät myös paalien silppuamisen.

Kuvan 1 tuloksia verrattiin myös TTS Tutkimuksen keräämiin toteutuneisiin urakointihintatilastoihin (Palva 2013). Irtosäilörehun tuubipakkaus ja paalien tuubikäärintä ovat Suomessa vielä sen verran harvinaisia menetelmiä, ettei niistä ole käytettävissä toteutuneita hintoja. Ajosilppuriketjussa, jossa rehu varastoidaan laakasiiloon, TTS:n tilaston hinnoilla laskettaessa kustannukset olivat noin $29 \%$ kuvan 1 kustannuksia korkeammat. Pyöröpaalausketjussa (kombi) TTS:n tilaston toteutuneet kustannukset olivat jopa 55 \% kuvan 1 kustannuksia korkeammat. Ilmeisesti erityisesti pyöröpaalausketjun taksoissa on mukana pienten lohkojen, runsaan siirtoajon ja alhaisten satojen aiheuttamaa hintalisää.

Koneiden ja rakennusten kustannuksista suuri osa on kiinteitä (korko ja poisto), eli suhteellisen riippumattomia käyttömääristä. Mallin avulla haluttiin tutkia sitä, kuinka paljon säilörehun korjuuseen hankitun kaluston kustannukset alenisivat, jos sille tulisi merkittävä määrä uutta käyttöä vuosittain, eli tässä tapauksessa biokaasunurmen korjuuta.

Kuvan 2 mukaan koneiden hehtaarikohtaiset kustannukset alenevat jyrkästi käyttömäärän kasvaessa 100 ha:sta 300 ha:iin vuodessa, minkä jälkeen lasku on maltillisempaa. Jos esimerkiksi ajosilppurin vuotuinen käyttömäärä kaksinkertaistuu 400 ha:sta 800 ha:iin, korjuukustannukset alenevat laskennallisesti 29 e/ha eli sadon ollessa 4 ton ka/ha alenema on noin 7,3 e/ton ka. Toisaalta tilanne ei ole välttämättä näin selkeä, koska käyttömäärän voimakkaasti kasvaessa, kone täytyy vaihtaa pikemmin uuteen. Asiaa pitäisi kysyä myös töitä tekeviltä yrittäjiltä, todennäköisesti heidän mielestään ha- tai tuntikustannusta ei voi alentaa juuri edellä mainitusta syystä. 


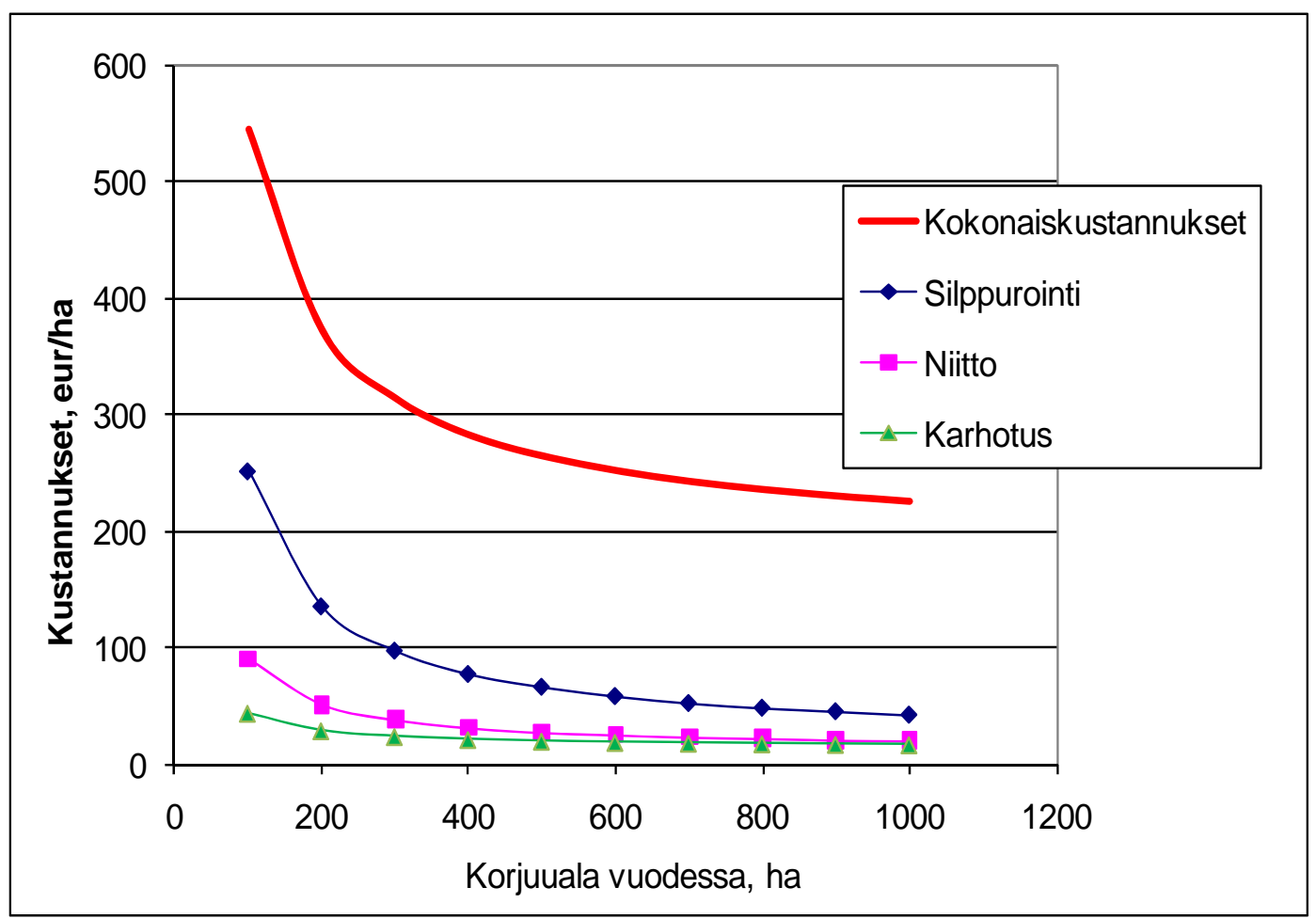

Kuva 2. Ajosilppuriketjun koneiden ha-kustannukset vuotuisen käyttömäärän kasvaessa.

Myös eri korjuu- ja varastointiketjujen herkkyyttä peltojen ja biokaasulaitoksen väliselle keskietäisyydelle ja esim. varastoinnissa käytettävän muovin hinnan muutoksille tarkasteltiin. Silppurikorjuun kustannukset ovat paalauskorjuuta alemmat, ja laskelman mukaan vasta n. 25-30 km kuljetusetäisyydellä paalausketju tulisi tarkkuussilppurikorjuuta edullisemmaksi (kuva 3). Tällöin silppuriketjussa täytyisi olla jo 9 perävaunuyhdistelmää siirtämässä rehua.

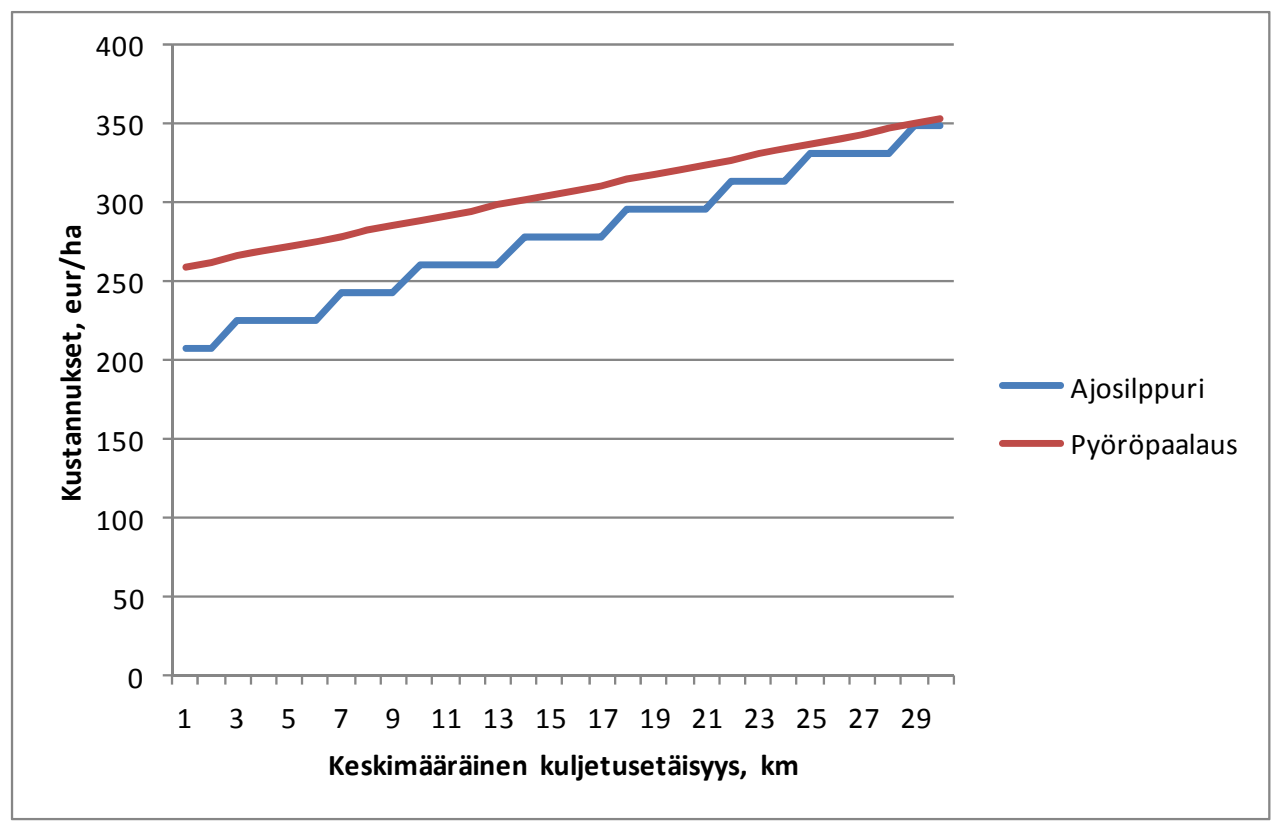

Kuva 3. Ajosilppuri- ja pyöröpaalausketjun hehtaarikustannus keskimääräisen kuljetusetäisyyden muuttuessa.

Jos käärintä- ja aumamuovin hinta nousisi 1,5 kertaiseksi, silppuriketjun kustannukset nousisivat vain 0,3 eur/ton ka, mutta yksittäispaalauksessa kustannusnousu olisi 6,3 eur/ton ka. Pyöröpaalien tuubikäärinnässä kustannukset nousisivat 2,6 eur/ton ka. 
Hehtaarisadon lisääntyminen 4:stä 7 tonniin ka/ha alensi kustannusta 4 - 6 eur/ton ka. Sadon korjaaminen kahdessa erässä yhden korjuukerran sijasta puolestaan kasvatti korjuukustannusta 5 - 8 eur/ton ka. Mallissa on käytössä tuntipohjainen hinnoittelu, jolloin korjuukertojen lisääminen ei kovin suuresti vaikuta tonnikohtaiseen korjuukustannukseen. Sen sijaan, jos urakoitsija käyttää hehtaarikohtaista hinnoittelua kaikissa työvaiheissa, voi korjuukertojen lisääntyminen yhdestä kahteen jopa kaksinkertaistaa tonnikohtaisen korjuukustannuksen.

Lisäksi arvioitiin, olisiko HVP- nurmeen perustuva sähköä ja lämpöä tuottava biokaasulaitos kannattava. Laskelma on lähinnä suuntaa antava, sillä kannattavuusselvitys ei ollut tämän hankkeen alunperäinen tavoite. Toisaalta kokonaisuudesta ja toimintaedellytyksistä on tarpeen saada suuntaa antava käsitys. Ederin (2012) mukaan peltobiomassaa käyttävän biokaasulaitoksen yksikkökustannukset eivät merkittävästi enää alene, kun laitoskoko ylittää 500 kW:n sähkötehon. Tällaisen laitoksen lämpöteho on noin $1 \mathrm{MW}$ ja investointikustannukset luokkaa 2,2 meur (4 $400 \mathrm{eur} / \mathrm{kW}_{\mathrm{el}}$ ). Investointikustannukset voivat tosin vaihdella paljonkin, eikä niistä ole kirjallisuudessa yksimielisyyttä. Korkotasona käytettiin 5 \% ja takaisinmaksuaikana 15 v. Tuotetun kaukolämmön hinnaksi oletettiin 65 eur/MWh. HVP-nurmea tämänkokoinen laitos tarvitsisi 830 ha, jos keskisato olisi laskelmissa käytetty 4 ton $\mathrm{ka} / \mathrm{ha}$.

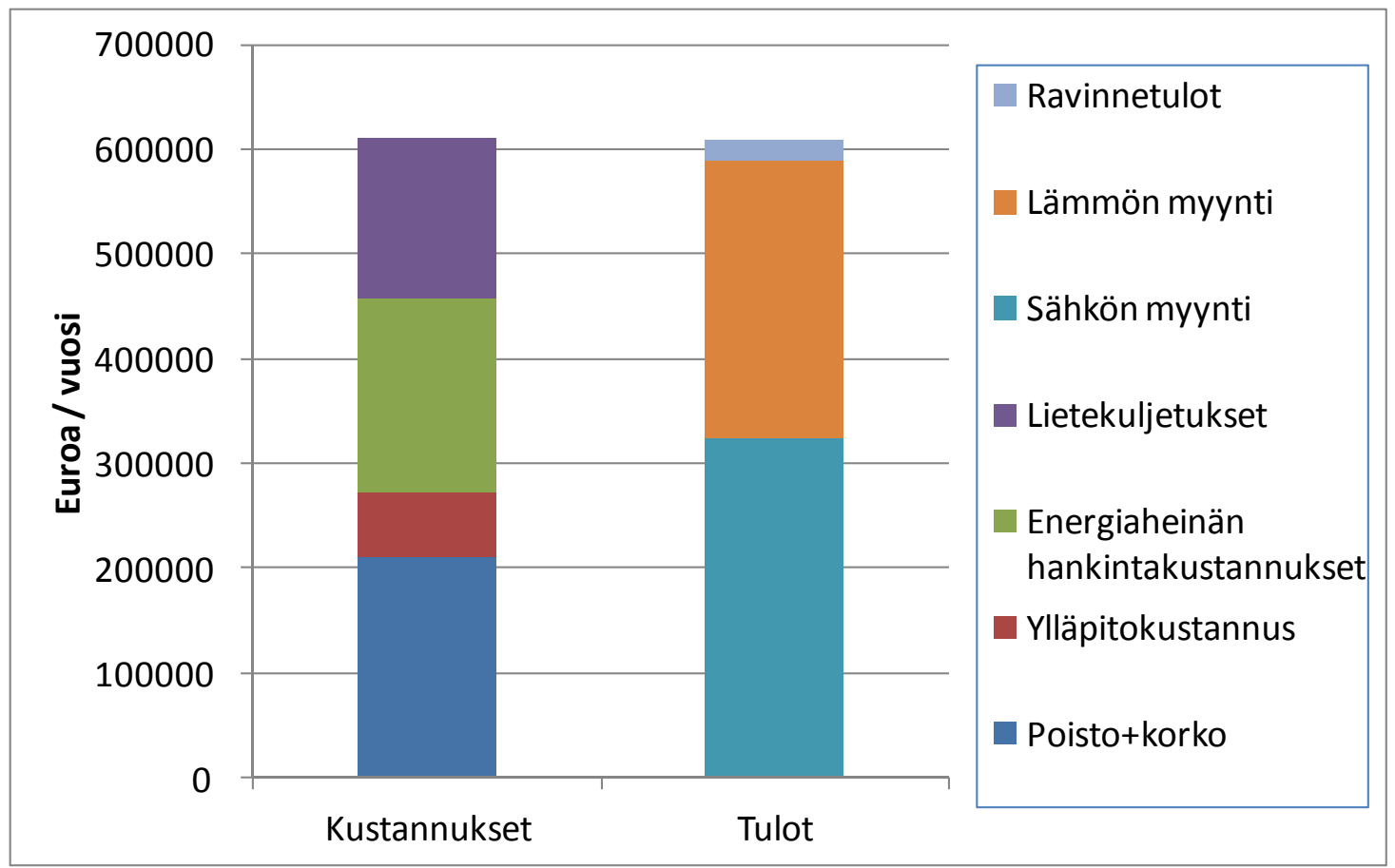

Kuva 4. Pelkästään nurmea käyttävän biokaasulaitoksen menot ja tulot (huom! Laskelma on lähinnä suuntaa antava). Laitoksen sähköteho 0,5 MW ja lämpöteho $1 \mathrm{MW}$. Energiaheinälle ei voida maksaa kantohintaa ja kaikki lämpö pitäisi saada hyötykäyttöön, jotta laitos olisi kannattava. Syöttötariffi on huomioitu tuloissa (lähteet: Eder 2012, Taavitsainen 2011).

Tämänkokoinen laitos voi saada joko investointitukea tai syöttötariffin mukaisen korkeamman sähkönhinnan, max. 13,5 c/kWh, jos lämpö käytetään hyödyksi. Esimerkkitapauksessa syöttötariffin valitseminen oli kannattavampi vaihtoehto. Biokaasulaitoksen saaminen kannattavaksi näyttää haasteelliselta, mutta ei aivan mahdottomalta (kuva 4). Lämpö olisi saatava myytyä täysimääräisesti, heinälle ei voida maksaa kantohintaa sekä korjuu- ja varastointikustannukset on saatava 55 eur/ton ka tuntumaan. Lisäksi laitoksen ei ole oletettu tuottavan alkuvaiheessa minkäänlaista voittoa, mikä voisi olla tarpeen riskitekijöiden torjumiseksi.

Laitoksen kannattavuutta tarkasteltiin myös siten, että laitosta käytettäisiin vain 7 kk:n ajan vuodessa. Tällöin lämmön saaminen kaupaksi täydellä hintaa olisi todennäköistä. Korko- ja poistokustannukset ovat kuitenkin niin suuret, ettei tämä vaihtoehto ollut kannattava. 


\section{Johtopäätökset}

Korjuu- ja varastointikustannukset olivat halvimmillaan tarkkuussilppuriketjulla (54 e/ton ka) ja kalleimmillaan pyöröpaalausketjulla (68 e/ton ka). Kustannustaso on melko korkea suhteessa saatavan energian arvoon. Biokaasulaitoksen kannalta kustannukset olisi saatava painettua mahdollisimman alas. Kustannustaso 55 e/ton ka on kaasulaitoksen talouslaskelman valossa siedettävä taso.

Koneiden vuotuinen käyttömääräoletus $(\mathrm{h} / \mathrm{v})$ vaikuttaa paljon varsinkin kalleimpien koneiden kustannuksiin. Koneiden kulumisen ja uusimistarpeen lisääntymisen arviointi käyttömääriä kasvatettaessa on haasteellista. Biomassanurmi voi tarjota urakoitsijoille uusia työmahdollisuuksia säilörehunkorjuuajan ulkopuolella ja siten auttaa alentamaan konekustannuksia.

Pyöröpaalausketjussa säilöntämuovin hinnan nousu vaikuttaa radikaalisti kustannuksiin, mutta silppuriketjussa vain vähän. Kustannusten säästämiseksi biokaasunurmi kannattaa pyrkiä korjaamaan vain kerran kesässä kahden korjuukerran sijasta, jos tämä on laatutekijöiden puolesta mahdollista.

Viljelijöiden voisi olla perusteltua luopua HVP-heinästä ilmaiseksi, jos biokaasulaitos hoitaisi korjuun ja ravinteet palautettaisiin korvauksetta tilan peltolohkoille. Erityisesti luomuviljelijöille tämä voisi olla hyvä vaihtoehto, koska tällöin he saisivat siirrettyä viherlannoitusvaikutusta HVP-lohkojen ulkopuolisille lohkoille. Tämä tietysti edellyttää, että kaasutukseen käytetyt raaka-aineet sopivat luomutuotantoon.

Biokaasu-CHP-laitoksessa lämmön myynnin arvolla on yhtä suuri merkitys kuin sähkön myynnin arvolla. Laskelmaesimerkissämme oletuksista haasteellisin lienee lämmön täysimääräisen myynnin toteutuminen. Varsinkin kesäaikaan tuloja voi jäädä lämmöstä saamatta. Jos lämpötulot jäävät saamatta 6 kk:n ajalta vuodessa, laitoksen kannattavuus heikkenee yli 100000 eur/v tappiolliseksi. Laitoksen olisi hyvä sijaita lähellä suurta kaukolämpöverkostoa, jotta lämmölle olisi kysyntää käyttöveden muodossa kesälläkin. Myös esimerkiksi sahatavaran, hakkeen ja viljan kuivaaminen saattaisivat hyödyntää osan lämmöstä kesäaikaan.

Alustavien laskelmien mukaan maatilakokoluokan biokaasulaitoksen (noin $100 \mathrm{~kW}_{\mathrm{el}}$ ) kannattavuus HVP-heinällä näyttää selvästi heikommalta kuin suuremman, luokkaa $500 \mathrm{~kW}_{\mathrm{el}}$ tehoisen laitoksen kannattavuus.

Käytännössä tämänkokoista laitosta tuskin suunniteltaisiin pelkän HVP-heinän varaan, vaan syötteitä olisi useita, joista HVP-heinä voisi muodostaa merkittävän osan. Biokaasusähkö kaipaisi lisää kannustimia (mm. korkeampaa sähkön hintaa), jotta sen tuottaminen HVP-heinällä olisi taloudellisesti järkevää. Lisäksi hukkalämmölle pitäisi kehittää järkeviä käyttökohteita. Jos kaasu jalostettaisiin liikennepolttoaineeksi, kannattavuus voisi olla parempi kuin sähköntuotannossa.

\section{Kirjallisuus:}

Eder, M. 2012. Biokaasulaitosten kannattavuustekijöitä. Suomessa 27.10.2012 pidetyn esitelmän moniste. 19 s.

Niemeläinen, O., Virkkunen, E., Jauhiainen, L. ja Lötjönen, T. 2012. Kuinka paljon viherkesanto- ja hoidettu viljelemätön pelto -lohkoilla olisi satoa biokaasun tuotantoon? Maataloustieteen Päivät 2012. www.smts.fi

Palva, R. 2013. Konetyön kustannukset ja tilastolliset urakointihinnat. TTS:n tiedote 3/2013 (645). 12 s.

Taavitsainen, T. 2011. Biokaasuteknologian edistäminen Pohjois-Savossa - Kestävä uusiutuvan energian tuotanto ja ravinteiden kierrätys (BIOTILA -hanke). Liiketoimintaosa-alueen loppuraportti. Envitecpolis. 88 s. 